\title{
Guest Editorial Foreword to the Special Issue of the XIII Symposium on Virtual and Augmented Reality
}

This special issue of the JIS (SBC Journal on 3D Interactive Systems) is in the second year acknowledging the best papers of the Symposium on Virtual and Augmented Reality. In the SVR 2011 several interesting research projects in the field of Virtual and Augmented Reality appeared and among the best papers this issue presents two selected papers for the readers of JIS. The SVR is the most important event on Virtual and Augmented Reality in Brazil, which is being conducted by academic professionals' members of the Brazilian Computer Society (SBC) that is supporting the conference for many years.

The two papers in this issue were selected among the best papers presented at the SVR 2011. Although the technical implementation of the papers is different each other, they try to solve problems of communication and location. It is possible to note that the virtual and augmented reality is really changing our life style, and these papers show important ideas that can be directly applied by people around the world.

The paper "xGroupware: Supporting Collaborative CrossReality Environments using Multiagents System" authored by Katia Vega, Débora Cardador, Hugo Fuks and Carlos Lucena, presents very modern proposals of meetings, combining the virtual and real in a way that users can really take advantage of the resources available to improve their communication. It is also important to say that the clever idea to use multi agents in the system as an autonomous way to perceive and interact with the situations of the meetings is amazing. Finally the integration of wearable computing devices in the system makes it very interesting and probably reflects meetings of the future.

The second paper "A Case Study of Augmented Reality for Mobile Platforms" authored by Gabriela Tinti Vasselai, Dalton Solano dos Reis and Paulo Cesar Rodacki Gomes presents how the mobile devices can contribute to help our localization with the resources of augmented reality. The paper shows that the resources available in the mobile devices can be used to augmented reality purposes although some improvements in the mobile platforms must be done.
We would like to thank all the reviewers of the process, the editors and staff that supported us with the submission system, and of course the authors that had to extend and adapt their papers in order to have some new content that makes this special issue an important reference point for virtual and augmented reality research.

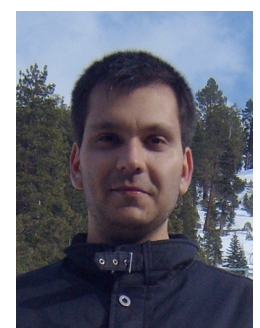

Luciano Pereira Soares holds a PhD in Electrical Engineering from Polytechnic School, University of São Paulo in Brazil. He was a postdoctoral research at the Instituto Superior Técnico in Portugal, Institut National de Recherche en Informatique et en Automatique in France and Instituto Superior de Ciências do Trabalho e da Empresa in Portugal. His research interests include, immersive multi-projection systems, real-time 3D computer graphics and high performance computing. He is currently a researcher at the Tecgraf, Computer Graphics Technology Group in PUC-Rio working in several projects with Petrobras, and Associate Professor at the Centro Universitário da Cidade do Rio de Janeiro.

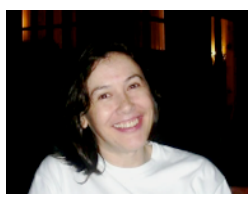

Veronica Teichrieb holds a PhD in Computer Science from Federal University of Pernambuco, in Brazil, having participated in a doctoral sandwich program at Aero-Sensing Radarsysteme $\mathrm{GmbH}$, in Germany. Currently, she is an associate professor at Informatics Center of the Federal University of Pernambuco, and research leader of the Voxar Labs. Her research interests include augmented reality, undertaking tracking, visualization and interaction related problems.

Luciano Pereira Soares - PUC-Rio Ipsoares@tecgraf.puc-rio.br

Veronica Teichrieb - UFPE vt@cin.ufpe.br 